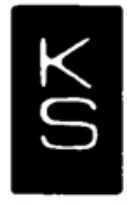



Dorothée Klaus ·

Palestinian Refugees in Lebanon 


\author{
begründet \\ von \\ Klaus Schwarz \\ herausgegeben \\ von \\ Gerd Winkelhane
}


ISLAMKUNDLICHE UNTERSUCHUNGEN • BAND 255

\section{Dorothée Klaus}

\section{Palestinian Refugees in Lebanon - Where to Belong?}




\section{Bibliografische Information Der Deutschen Bibliothek}

Die Deutsche Bibliothek verzeichnet diese Publikation in der Deutschen Nationalbibliografie; detaillierte bibliografische Daten sind im Internet über http://dnb.ddb.de abrufbar.

Alle Rechte vorbehalten.

Ohne ausdrückliche Genehmigung des Verlages

ist es nicht gestattet, das Werk oder einzelne Teile daraus

nachzudrucken oder zu vervielfältigen.

(c) Gerd Winkelhane, Berlin 2003.

Klaus Schwarz Verlag GmbH, Postfach 4102 40, D-12112 Berlin ISBN 3-87997-311-3

Druck: Offsetdruckerei Gerhard Weinert GmbH, D-12099 Berlin

ISSN 0939-1940

ISBN 3-87997-311-3 